
3 Research Square
Preprints are preliminary reports that have not undergone peer review.
They should not be considered conclusive, used to inform clinical practice,
or referenced by the media as validated information.

\title{
Characteristics of breast cancer patients tested for germline BRCA1/2 mutations by next-generation sequencing in Ramathibodi Hospital, Mahidol University
}

Songporn Oranratnachai

Mahidol University Faculty of Medicine Ramathibodi Hospital

Watchalawalee Yamkaew

: Mahidol University Faculty of Medicine Ramathibodi Hospital

Atchara Tunteeratum

: Mahidol University Faculty of Medicine Ramathibodi Hospital

Thongchai Sukarayothin

: Mahidol University Faculty of Medicine Ramathibodi Hospital

Nareenart lemwimangsa

: Mahidol University Faculty of Medicine Ramathibodi Hospital

Ravat Panvichian ( $\nabla$ ravat.pan@mahidol.ac.th )

Mahidol University Faculty of Medicine Ramathibodi Hospital https://orcid.org/0000-0001-5282-8166

Research Article

Keywords: Breast cancer, BRCA1/2 mutations, Luminal subtype, HER2-positive, Prognosis, Next-generation sequencing (NGS)

Posted Date: June 15th, 2021

DOI: https://doi.org/10.21203/rs.3.rs-591403/v1

License: (c) (1) This work is licensed under a Creative Commons Attribution 4.0 International License. Read Full License 


\section{Abstract}

Germline mutations in BRCA1/2 are the most common cause of hereditary breast and ovarian cancer (HBOC) syndrome. A few studies have reported the prevalence of germline BRCA mutations in Asian patients with breast cancer. Here, we aimed to explore the prevalence and characteristics of breast cancers in Thai patients with germline BRCA1/2 mutations. We retrospectively reviewed breast cancer patients tested for germline BRCA1/2 mutations in our institute during 2014-2018. BRCA mutations were detected using next-generation sequencing and confirmed using Sanger sequencing. We analyzed the characteristics of patients with or without BRCA mutations, disease-free survival (DFS), and associated factors. Among the 67 included patients, 12 (18\%) were BRCA1/2 carriers ( 6 each), 4 (6\%) harbored variants of uncertain significance, and 51 (76\%) were non-carriers. We discovered two novel frameshift mutations in BRCA2 (c.2380delA and c.8855dupT). Mean ages at breast cancer diagnosis in BRCA1 carriers, BRCA2 carriers, and non-carriers were 39.8, 46.2, and 42.0 years, respectively. The 12 tumors of BRCA carriers were mostly the luminal-B subtypes. Two of these tumors were HER2-positive luminal-B; however, the triple-negative subtype was not observed. After adjusting for stages and luminal subtypes, BRCA carriers experienced worse 3-year DFS than non-carriers (81.5\% vs. 90.3\%, HR 2.04 (0.64-6.49), P = 0.229). The stage at diagnosis was the sole factor significantly associated with 3 -year $D F S(100 \%, 84.8 \%$, and 72.7\%; stages I, II, and III, respectively). In summary, breast cancers in Thai patients with germline BRCA1/2 mutations were mostly the luminal-B subtypes and experienced a worse prognosis than those without mutations.

\section{Introduction}

Breast cancer is the most frequently diagnosed cancer and the leading cause of cancer death among females in most countries [1]. In Thailand, breast cancer is the third most frequent cancer and the third most common cause of cancer death of both sexes [2]. Breast cancer, which primarily occurs in women and 1\% of men, is typically acquired through multistep accumulations of somatic mutations, whereas $5-10 \%$ of breast cancers are inherited through germline mutations. Germline mutations in the breast cancer susceptibility genes, BRCA1 and BRCA2, are the most common causes of hereditary breast and ovarian cancer (HBOC) syndrome [3]. A large prospective study found that women who inherit deleterious germline mutations of BRCA1 or BRCA2 have very high cumulative risks for developing breast cancer (e.g., risks to 80 -year-olds are $72 \%$ and 69\% for BRCA1 and BRCA2 carriers, respectively) [4].

The main characteristics of patients with breast cancer with BRCA mutations include a family history of breast cancer, younger age at diagnosis, male breast cancer, or multiple tumors (bilateral breast cancer or breast and ovarian cancer) in the same patient [5]. Furthermore, patients with BRCA1 mutations are most commonly younger at diagnosis and associated with the triple-negative breast cancer (TNBC) subtype. In contrast, patients with BRCA2 mutations are mainly associated with estrogen receptor (ER)-positive breast cancer [6-8]. Furthermore, a more advanced stage at diagnosis and the presence of multiple foci of breast cancers are more common in patients with BRCA1 and BRCA2 mutations compared with patients with sporadic tumors. Abundant data show that patients with breast cancer with BRCA1/2 mutations (BRCA carriers) experience higher mortality rates than non-carriers [5, 8].

BRCA1 and BRCA2 are tumor suppressor genes located at chromosome 17q21 and 13q12.3, respectively [9-12]. BRCA1 and BRCA2 proteins are essential for repairing DNA-double strand breaks (DSBs) by homologous recombination, cell growth regulation, and control of cell division [3, 13, 14]. Genetic alterations of these genes occur in $5 \%$ of all breast cancers and $15-25 \%$ of familial breast cancers worldwide $[7,15]$. The prevalence and phenotype of BRCA mutations vary according to country and race. The prevalence of BRCA mutations depends on the risk of breast cancer development; namely, a low prevalence in patients with sporadic breast cancer, but higher in selected high-risk cases such as breast cancer with a strong family history, bilateral breast cancer, and multiple organ cancer. Only a few studies have investigated the prevalence of BRCA mutations in Asian patients with breast cancer. Data from Korea shows a BRCA1/2 prevalence of $8.9 \%$ in high-risk patients without family history and $22.3 \%$ in patients with family history [16]. In China, the prevalence of BRCA1/2 in high-risk patients is $9.1 \%$, but only $3.5 \%$ in sporadic breast cancer patients [17]. Similarly, there is limited data on the prevalence and characteristics of BRCA-associated breast cancer in Thailand. Only two studies have investigated BRCA1/2 mutations in selected Thai patients with breast cancer with and without familial history of $\mathrm{HBOC}[18,19]$. One group of investigators in Thailand used the Multiplex Ligation dependent Probe Amplification (MLPA) method to screen for BRCA1/2 large genomic rearrangement in Thai patients with familial breast cancer; they only found BRCA1 alteration in $1 \%$ of high-risk patients with breast cancer [19].

Sanger sequencing is the gold standard for germline BRCA mutation testing. Unfortunately, Using Sanger sequencing in a routine setting is considered too time-consuming and costly due to the nature of germline BRCA1/2 mutation, which is not clustered in any specific exon region. Next-generation sequencing (NGS) offers a promising alternative for BRCA testing because it takes a shorter turnaround time and relatively inexpensive compared with conventional Sanger sequencing. However, NGS requires a dedicated system operated by skilled technicians and requires complex data analysis.

Before the approval of a poly(adenosine diphosphate [ADP]-ribose) polymerase (PARP) inhibitor for patients with breast cancer with BRCA mutations [20], few testing sites were available in Thailand. This is likely explained by the limited number of testing laboratories, the lack of geneticists offering pre-and posttest counseling, and costly out-of-pocket payments.

The Center for Medical Genomics (CMG) Ramathibodi Hospital started using NGS for routine BRCA mutation testing in 2014. The number of BRCA mutation testing services in Thailand recently increased since the approval of PARP inhibitors as the treatment for cancers with BRCA mutations. In the present study, we explored the prevalence and characteristics of breast cancers in Thai patients tested for germline BRCA1/2 mutations.

\section{Methods}

\section{Patients}

We first screened all patients tested for germline mutations of BRCA1 and BRCA2 at the CMG Ramathibodi Hospital from January 2014 to December 2018. We excluded patients with cancers other than breast cancer or patients with breast cancer who enrolled in other clinical studies; we also excluded those whose 
data in the electronic medical records (EMRs) of Ramathibodi Hospital were unavailable. The EMRs were retrospectively reviewed. We collected demographic data at diagnosis, including sex, age, and Eastern Cooperative Oncology Group (ECOG) performance status as well as TNM staging according to AJCC 8th edition [21]. Besides, we also collected tumor characteristics, including pathological subtype, histological grading, ER, progesterone receptor (PR), human epidermal growth factor receptor (HER2), and Ki-67 status as described in the pathological reports. There are some variations from time to time in the reporting systems for ER and PR immunohistochemistry (IHC) staining. In the present study, ER and PR were considered negative if the nuclei of tumor cells were stained $<1 \%$. HER2 expression, which was routinely assessed through IHC staining intensity, was classified as negative, $1+, 2+$, or $3+$. Furthermore, fluorescence in situ hybridization (FISH) was performed to confirm and document registration for trastuzumab reimbursement. Luminal subtypes were classified according to the Saint Gallen Guidelines 2015 [22]. Treatments and outcomes such as surgical management, adjuvant therapies, recurrent/metastasis of disease, secondary primary cancer, and death were also collected.

The Ethics Committee on Human Rights related to research involving human subjects, Faculty of Medicine, Ramathibodi Hospital, Mahidol University approved this study (MURA2019/988).

\section{Analysis of germline mutations in BRCA1 and BRCA2 detected by NGS}

Genomic DNA was extracted from the peripheral blood of patients. Analyses of germline mutations of BRCA1 and BRCA2 were performed using NGS at the CMG. All coding regions in BRCA1 and BRCA2 were sequenced, aligned with the Homo sapiens genome assembly GRCh37 (hg19) published by the Genome Reference Consortium [23, 24]. Sequence variants were classified in decreasing order of clinical importance as "Pathogenic," "Likely pathogenic," "Variants of Uncertain Significance (VUS)," "Likely benign," or "Benign," according to the American College of Medical Genetics and Genomics (ACMG) Standards and Guidelines [25]. Selected variants identified as "Pathogenic" or "Likely pathogenic" were confirmed using Sanger sequencing.

\section{Statistical analysis}

Descriptive statistical analysis was used to describe patients' characteristics. Clinical characteristics were expressed as numbers and percentages for categorical variables, and continuous data were expressed as the mean \pm standard deviation (SD). Comparisons of characteristics between carriers of BRCA1/2 and non-carriers were performed using Fisher's exact test for categorical variables and one-way analysis of variance for continuous variables; Pvalue $<0.05$ indicates a significant difference. Disease-free survival (DFS) was defined as the time from the date of diagnosis to the date of the first event (local recurrence or distant metastasis, or second primary cancer, or death from any cause). Patients who were alive without disease recurrence were censored at the cut-off date (December 31, 2019). Median DFS was estimated using the Kaplan-Meier method. To identify prognostic factors of DFS, we applied Cox regression analysis. BRCA status, stage at diagnosis, and luminal subtypes, along with variables with P-value less than 0.1 from the univariate Cox regression model, were adjusted by multivariate analysis. Stata software, version 16, was applied to perform all analyses [26].

\section{Results}

\section{Pathogenic germline mutations of BRCA1/2}

One hundred forty-two patients had been tested for germline mutations of BRCA1/2 by NGS at CMG from January 2014 to December 2018 . Seventy-five patients were excluded for reasons, as described in Fig. 1. Finally, 67 patients with breast cancer were included in this study. The majority of the included patients $(51,76.1 \%)$ were regarded as high risk for HBOC (diagnosed with breast cancer at $\leq 40$ years or TNBC at $\leq 60$ years, male breast cancer, bilateral breast cancer, or multiple organ cancers).

Pathogenic BRCA mutations confirmed using Sanger sequencing were detected in 12 (17.9\%) patients (6 BRCA1 carriers and 6 BRCA2 carriers). VUS were detected in 4 (6.0\%) patients, and the others were BRCA non-carriers. Among the 12 mutations identified, 5 were frameshifts, 4 were nonsense, 2 were at splice acceptor positions, and 1 was missense. The mutations in BRCA1 were clustered in specific exonic regions, and the mutations of BRCA2 were more widely distributed across exonic regions. The positions of these BRCA1/2 mutations were shown in Fig. 2. Among the 6 pathogenic mutations in BRCA1, 3 were located in exon 10 and 3 in exon 16. Among the 6 pathogenic mutations of BRCA2, 3 were located in exon 11, 2 in exon 22 , and 1 in exon 25.

We discovered two novel frameshift mutations in BRCA2 [c.2380delA (p.Met794Cysfs) and c.8855dupT (p.Met2952llefs)]. We detected the another BRCA2 mutation [c.8888_8889insA (p.Arg2964Lysfs)] reported in previous studies from China and Singapore [27, 28]. The other nine mutations detected here were reported in previous studies of patients residing in Asia, the United States, and Europe (ClinVar [29] or HGMD databases [30]). The characteristics of the BRCA carriers and associated mutations were presented in Table 1. We detected 5 VUS of BRCA2 in 4 of 67 (6.0\%) patients. All were missense mutations, and one of the patients carried two VUS. VUS were not detectable in BRCA1 (Fig. 2).

\section{Patients' Clinical Characteristics And Dfs}

Among 67 patients, $98.5 \%$ were female, except one male with breast cancer who was a BRCA non-carrier. The mean age at diagnosis of breast cancer was $42.0 \pm 10.3$ years (BRAC1, $39.8 \pm 7.4$ years; BRCA2, $46.2 \pm 16.0$ years). Among 10 (14.9\%) patients with bilateral breast cancer, 4 had synchronous lesions, and 6 had metachronous lesions. Most patients presented with early-stage breast cancer, and $50 \%$ had stage II disease. BRCA carriers and VUS patients tended to be luminal B subtypes, whereas the most common tumor subtype of non-carriers was TNBC (27.4\%), followed by the HER2-negative luminal-B subtype (21.6\%). Patients' demographic data were presented in Table 2.

Surgery was performed on $98.5 \%$ of patients, including mastectomy $(n=51)$ and breast-conserving surgery $(B C S)(n=15)$. Almost all BRCA carriers underwent mastectomy, except one who underwent BCS and was subsequently found to harbor a BRCA mutation. Adjuvant radiotherapy was administered to $56.7 \%$ of patients for locally advanced breast cancer (T3-T4) and lymph node metastasis. Adjuvant chemotherapy was provided to $66 \%$ of patients; 19 (28.4\%) 
patients received only anthracycline-based chemotherapy, 16 (23.9\%) patients received sequential treatment with anthracycline-based followed by a taxane, 2 patients received taxane-based chemotherapy, and 7 patients received other regimens. Platinum-based adjuvant chemotherapy was not used. Patients with hormone receptor-positive breast cancer underwent adjuvant endocrine therapy. Trastuzumab was used as a 1-year adjuvant treatment for 16 confirmed HER2-positive patients.

Among 12 tumors of BRCA carriers, 8 were the HER2-negative luminal-B, and 2 were the HER2-positive luminal-B subtype. Unexpectedly, the TNBC subtype was not observed among the BRCA carriers. The clinicopathological features of BRCA1 and BRCA2 carriers were summarized in Table 3 .

The results of subgroup analysis of BRCA non-carriers were shown in Supplementary Table S1. Overall, there were no significant differences in clinical and pathological characteristics between early-onset ( $\leq 40$ years) and late-onset ( $>40$ years) patients; however, early-onset patients received adjuvant chemotherapy at a significantly higher frequency compared with late-onset patients $(P=0.017)$. Early-onset patients tended to have higher grades and stages compared with late-onset patients.

At the cut-off date (December 31, 2019), the median follow-up was 2.7 years (range 0.2-17.2 years), 51 patients were disease-free, 16 experienced a second primary tumor $(n=8)$, distant metastases $(n=7)$, or local recurrence $(n=1)$. Among the seven patients who developed metastasis, 2 were BRCA carriers, 1 had VUS, and 4 were BRCA non-carriers; 6 patients received palliative chemotherapy, and 1 patient received palliative endocrine therapy. One BRCA carrier received platinum-based chemotherapy followed by a PARP inhibitor, and another BRCA carrier received anthracycline and cyclophosphamide.

The 3-year DFS rate was $87.7 \%$ (Table 4). BRCA1/2 carriers had lower 3-year DFS rates vs non-carriers, although the difference was not statistically significant (81.5\% vs $90.3 \%$, hazard ratio (HR) 95\% confidence interval (Cl), 2.04 (0.64-6.49); $P=0.229)$. Similarly, patients with VUS had inferior 3-year DFS compared with non-carriers (79.0\% vs $90.3 \%$; HR $(95 \% \mathrm{Cl}), 1.60(0.20-12.99) ; \mathrm{P}=0.658)$. TNM staging was a significant prognostic factor for 3 -year DFS, with higher stage associated with lower 3-year DFS. Three-year DFS rates were $100 \%, 84.8 \%$, and $72.7 \%$ for stages I, II, and III, respectively, with HR (95\% CI), 2.88 (0.7311.33); $P=0.131$ and 6.82 (1.12-41.33); $P=0.037$ for stages II and III compared with stage I, respectively.

After adjusting for the TNM stage and luminal subtypes using multivariate Cox regression analysis, BRCA1/2 carriers had inferior DFS compared with noncarriers, although the difference was not statistically significant, HR $(95 \% \mathrm{Cl}), 2.50(0.48,12.97) ; \mathrm{P}=0.275$. Similarly, patients with VUS had inferior DFS compared with non-carriers, $\mathrm{HR}(95 \% \mathrm{Cl}), 1.25(0.12-12.81) ; \mathrm{P}=0.852$. After adjustments in multivariate analysis, the TNM stage at diagnosis remained significantly associated with 3-year DFS. Stages II and III had inferior DFS compared with stage I, HR (95\% CI), $6.32(0.90-44.48)$; P = 0.064 and 16.30 (1.38192.81); $P=0.027$, respectively (Table 4).

\section{Discussion}

Among 67 patients included in the present study, we detected 6 (8.95\%) BRCA1 carriers, 6 (8.95\%) BRCA2 carriers, 4 (6.0\%) patients with VUS, as well as 51 (76.1\%) non-carriers. The 12 BRCA carriers had tumors mostly with luminal-B subtypes (8 HER2-negative luminal-B, 2 HER2-positive luminal-B, and 2 unclassified because of missing data for hormonal receptor and HER2). BRCA carriers had inferior 3-year DFS compared to non-carriers, although the difference was not statistically significant after adjusting for TNM stage and luminal subtype. The TNM stage at diagnosis was only the significant factor associated with 3-year DFS (higher stage lower 3-year DFS).

The majority of the previous reports from Thailand focused on BRCA in ovarian cancer [31,32]. In contrast, limited data are available regarding BRCA mutations in Thai patients with breast cancer. A few studies conducted in Thailand have included breast cancer in their report; one study investigated in the highly selective patients with breast and/or ovarian cancer with strong familial history of HBOC [18], and the other study screened for BRCA1/2 large genomic rearrangement with MLPA method in high-risk patients with familial breast cancer [19]. Our present retrospective study documents the prevalence and clinical characteristics of Thai patients with breast cancer, including BRCA carriers, non-carriers, and those with VUS as detected by NGS. Although most studies on BRCA1/2 mutations involved non-Asian populations, retrospective studies of high-risk Asian populations showed the frequencies of BRCA1 and BRCA2 mutations between $2.3 \%-18.6 \%$ and $2.3 \%-11.4 \%$, respectively [7]. Furthermore, data from Korea demonstrated the prevalence of BRCA1/2 carriers in high-risk patients without or with familial history of breast cancer between 8.9-22.3\% [16]. The prevalence of BRCA1/2 carriers in the Chinese population is 9.1\% [17]. Here we showed the frequencies of BRCA1 and BRCA2 mutations in high-risk Thai patients at $8.95 \%$ and $8.95 \%$, respectively, consistently with the previous studies $[7,16,17]$.

It is well accepted that family history, age at diagnosis, and race are predictive factors for the probability of an individual carrying a germline BRCA1/2 mutation [33,34]. Whereas the mean age at diagnosis of breast cancer in BRCA1/2 carriers and non-carriers was similar in the present study, the age at diagnosis of breast cancer in BRCA1 carriers was lower than that of BRCA2 carriers (39.8 years vs. 46.2 years), consistently with previous studies showing the age at diagnosis of breast cancer in BRCA1 and BRCA2 carriers ranging between 30-45 years [7,35]. BRCA1/2 carriers have a higher risk of developing contralateral or second primary breast cancer, with long term-risks ranging from $60 \%-70 \%$ [35]. In the present study, we found 3 out of 12 patients ( $25 \%$ ) with BRCA1/2 mutations that had bilateral breast cancer (one with metachronous bilateral breast cancer and two with synchronous bilateral breast cancer). This was siwmilar to a previous study in Korea finding $22.1 \%$ of BRCA1/2 carriers with bilateral breast cancer [36]. Breast cancer in BRCA1 carriers is typically associated with the TNBC subtype, and incidence of TNBC is higher in younger patients and lowered in the elderly [7,35,37]. Nevertheless, hormone receptorpositive breast cancers in BRCA1 carriers are detectable in the elderly and postmenopausal patients [38,39]. HER2 overexpression has been detected only in 0$8 \%$ of BRCA-associated breast cancer, lower than in sporadic breast cancer [35]. However, in the present study, all breast cancers of BRCA1 carriers were mostly the HER2-negative luminal-B subtype, the patients were younger (27-46 years), and the TNBC subtype was not observed. Furthermore, BRCA2 carriers in the present study had both HER2-negative luminal-B tumors and HER2-positive luminal-B tumors. Therefore, we should consider testing for BRCA germline mutation in patients suspected of $\mathrm{HBOC}$ presenting with luminal-B subtype breast cancer; this is relevant because BRCA carriers are candidates for specifiC 
treatments (platinum-based chemotherapy or PARP inhibitors) that increase response rates and prolong survival. Such patients with BRCA mutations are candidates for screening for BRCA-associated cancer other than breast cancer to detect the early-stage disease.

The outcomes of breast cancer in BRCA carriers were conflicting. Previous systematic reviews and a meta-analysis found significantly worse overall survival (OS) of BRCA carriers than non-carriers, although the difference in recurrence-free survival is not statistically significant [40,41]. Other studies conducted in France and Switzerland found significantly superior 5-year DFS of BRCA1 carriers, although 5-years DFS of BRCA2 carriers is not significantly better than noncarriers [42]. In contrast, a study conducted in Korea found significantly inferior 10-year DFS and more contralateral breast cancer in BRCA1/2 carriers than non-carriers, but no significant difference in 10-year OS [43]. Furthermore, a study of Korean patients found that clinical nodal status is the only significant factor associated with DFS, even after adjusting for clinical nodal stage, BRCA status, hormonal receptor status, and Ki-67. Consistent with these findings, in the present study, adjusted multivariate analysis revealed that the only significant factor associated with DFS was the stage at diagnosis, whereas BRCA1/2 carriers had inferior DFS compared with BRCA non-carriers; however, the difference was not statistically significant.

The strength of this study is the use of reliable and comprehensive NGS techniques to analyze BRCA sequences. Using NGS, novel genetic alterations could be found and graded. However, our study has some limitations, such as its retrospective analysis of patients tested at a single institution which primarily relied on affordable patients despite the indications for germline BRCA testing according to the NCCN guideline. Thus, it probably not represents the true prevalence of BRCA mutation in Thai patients. Moreover, we could not identify a significant association between BRCA status and clinical outcomes because of the study's relatively small sample size. To better identify the actual prevalence of germline BRCA mutations in Thai breast cancer patients, a multicenter prospective study with a larger number of subjects is required.

In summary, this study describes characteristics, treatment outcomes, and prognostic factors of patients with breast cancer treated at a single university hospital in Thailand. We found that breast cancer in BRCA carriers was significantly associated with the luminal-B subtype, and BRCA1 and BRCA2 carriers showed a trend of inferior 3-year DFS than non-carriers. A longer follow-up of this study is required to determine the long-term survival outcomes.

\section{Declarations}

\section{Funding}

This research did not receive any specific grant from funding agencies in the public, commercial, or not-for-profit sectors.

\section{Conflict of Interests}

All authors declare no conflict of interests.

\section{Competing interests}

The authors declare that they have no competing interests.

\section{Availability of data and material}

All data generated or analyzed during this study are included in this published article.

\section{Authors' contributions}

Songporn Oranratnachai (SO): Methodology, Formal analysis, Visualization, Writing - Original draft, and contributed to every draft thereafter. Watchalawalee Yamkaew (WY): Data curation, Visualization, Writing - Original draft, and contributed to every draft thereafter. Atchara Tunteeratum (AT): Supervision and contributed to later drafts of the manuscript. Thongchai Sukarayothin (TS): Supervision and contributed to later drafts of the manuscript. Nareenart lemwimangsa (NI): Resource, Formal analysis, and contributed to later drafts of the manuscript. Ravat Panvichien (RP): Conceptualization, Writing - Review and editing, and contributed to later drafts of the manuscript. All authors analyzed the results, read, and approved the manuscript for submission.

\section{Ethics approval and consent to participate}

The Ethics Committee on Research involving Human Subjects of the Faculty of Medicine, Ramathibodi Hospital, Mahidol University approved this study. As this was a retrospective study of anonymized patients' data, informed consent was not required.

\section{Consent for publication}


Not applicable

\section{Acknowledgments}

The authors would like to express special thanks to all staffs at Center for Medical Genomics, Faculty of Medicine, Ramathibodi Hospital, Mahidol University, Bangkok, Thailand for their kind assistance. We thank Edanz (https://www.edanz.com/ac) for editing a draft of this manuscript.

\section{References}

1. Sung H, Ferlay J, Siegel RL, Laversanne M, Soerjomataram I, Jemal A, Bray F (2021) Global cancer statistics 2020: GLOBOCAN estimates of incidence and mortality worldwide for 36 cancers in 185 countries. CA Cancer J Clin. doi:10.3322/caac.21660

2. World Health Organization (2020) Thailand - Global Cancer Observatory 2020. https://gco.iarc.fr/today/data/factsheets/populations/764-thailandfact-sheets.pdf. Accessed May 12021

3. Roy R, Chun J, Powell SN (2011) BRCA1 and BRCA2: different roles in a common pathway of genome protection. Nat Rev Cancer 12 (1):68-78. doi:10.1038/nrc3181

4. Kuchenbaecker KB, Hopper JL, Barnes DR, Phillips KA, Mooij TM, Roos-Blom MJ, Jervis S, van Leeuwen FE, Milne RL, Andrieu N, Goldgar DE, Terry MB, Rookus MA, Easton DF, Antoniou AC, Brca, Consortium BC, McGuffog L, Evans DG, Barrowdale D, Frost D, Adlard J, Ong KR, Izatt L, Tischkowitz M, Eeles R, Davidson R, Hodgson S, Ellis S, Nogues C, Lasset C, Stoppa-Lyonnet D, Fricker JP, Faivre L, Berthet P, Hooning MJ, van der Kolk LE, Kets CM, Adank MA, John EM, Chung WK, Andrulis IL, Southey M, Daly MB, Buys SS, Osorio A, Engel C, Kast K, Schmutzler RK, Caldes T, Jakubowska A, Simard J, Friedlander ML, McLachlan SA, Machackova E, Foretova L, Tan YY, Singer CF, Olah E, Gerdes AM, Arver B, Olsson H (2017) Risks of Breast, Ovarian, and Contralateral Breast Cancer for BRCA1 and BRCA2 Mutation Carriers. JAMA 317 (23):2402-2416. doi:10.1001/jama.2017.7112

5. Huszno J, Kolosza Z, Grzybowska E (2019) BRCA1 mutation in breast cancer patients: Analysis of prognostic factors and survival. Oncol Lett 17 (2):1986-1995. doi:10.3892/ol.2018.9770

6. Bayraktar S, Gutierrez-Barrera AM, Liu D, Tasbas T, Akar U, Litton JK, Lin E, Albarracin CT, Meric-Bernstam F, Gonzalez-Angulo AM, Hortobagyi GN, Arun BK (2011) Outcome of triple-negative breast cancer in patients with or without deleterious BRCA mutations. Breast Cancer Res Treat 130 (1):145-153. doi:10.1007/s10549-011-1711-z

7. Kwong A, Shin VY, Ho JC, Kang E, Nakamura S, Teo SH, Lee AS, Sng JH, Ginsburg OM, Kurian AW, Weitzel JN, Siu MT, Law FB, Chan TL, Narod SA, Ford JM, Ma ES, Kim SW (2016) Comprehensive spectrum of BRCA1 and BRCA2 deleterious mutations in breast cancer in Asian countries. J Med Genet 53 (1):15-23. doi:10.1136/jmedgenet-2015-103132

8. Haque R, Shi JM, Telford C, Avila C, Alvarado M, Tiller GE, Dalvi T, Gutierrez L, Tyczynski J, Kaye JA (2018) Survival Outcomes in BRCA1 or BRCA2 Mutation Carriers and the Influence of Triple-Negative Breast Cancer Subtype. Perm J 22:17-197. doi:10.7812/TPP/17-197

9. Hall JM, Lee MK, Newman B, Morrow JE, Anderson LA, Huey B, King MC (1990) Linkage of early-onset familial breast cancer to chromosome $17 q 21$. Science 250 (4988):1684-1689. doi:10.1126/science.2270482

10. Miki Y, Swensen J, Shattuck-Eidens D, Futreal PA, Harshman K, Tavtigian S, Liu Q, Cochran C, Bennett LM, Ding W, et al. (1994) A strong candidate for the breast and ovarian cancer susceptibility gene BRCA1. Science 266 (5182):66-71. doi:10.1126/science.7545954

11. Wooster R, Neuhausen SL, Mangion J, Quirk Y, Ford D, Collins N, Nguyen K, Seal S, Tran T, Averill D, et al. (1994) Localization of a breast cancer susceptibility gene, BRCA2, to chromosome 13q12-13. Science 265 (5181):2088-2090. doi:10.1126/science.8091231

12. Tavtigian SV, Simard J, Rommens J, Couch F, Shattuck-Eidens D, Neuhausen S, Merajver S, Thorlacius S, Offit K, Stoppa-Lyonnet D, Belanger C, Bell R, Berry S, Bogden R, Chen Q, Davis T, Dumont M, Frye C, Hattier T, Jammulapati S, Janecki T, Jiang P, Kehrer R, Leblanc JF, Mitchell JT, McArthur-Morrison J, Nguyen K, Peng Y, Samson C, Schroeder M, Snyder SC, Steele L, Stringfellow M, Stroup C, Swedlund B, Swense J, Teng D, Thomas A, Tran T, Tranchant M, Weaver-Feldhaus J, Wong AK, Shizuya H, Eyfjord JE, Cannon-Albright L, Tranchant M, Labrie F, Skolnick MH, Weber B, Kamb A, Goldgar DE (1996) The complete BRCA2 gene and mutations in chromosome 13q-linked kindreds. Nat Genet 12 (3):333-337. doi:10.1038/ng0396-333

13. Venkitaraman AR (2001) Functions of BRCA1 and BRCA2 in the biological response to DNA damage. J Cell Sci 114 (Pt 20):3591-3598

14. Gudmundsdottir K, Ashworth A (2006) The roles of BRCA1 and BRCA2 and associated proteins in the maintenance of genomic stability. Oncogene 25 (43):5864-5874. doi:10.1038/sj.onc. 1209874

15. Armstrong N, Ryder S, Forbes C, Ross J, Quek RG (2019) A systematic review of the international prevalence of BRCA mutation in breast cancer. Clin Epidemiol 11:543-561. doi:10.2147/CLEP.S206949

16. Kang E, Seong MW, Park SK, Lee JW, Lee J, Kim LS, Lee JE, Kim SY, Jeong J, Han SA, Kim SW, Korean Hereditary Breast Cancer Study G (2015) The prevalence and spectrum of BRCA1 and BRCA2 mutations in Korean population: recent update of the Korean Hereditary Breast Cancer (KOHBRA) study. Breast Cancer Res Treat 151 (1):157-168. doi:10.1007/s10549-015-3377-4 
17. Lang GT, Shi JX, Hu X, Zhang CH, Shan L, Song CG, Zhuang ZG, Cao AY, Ling H, Yu KD, Li S, Sun MH, Zhou XY, Huang W, Shao ZM (2017) The spectrum of BRCA mutations and characteristics of BRCA-associated breast cancers in China: Screening of 2,991 patients and 1,043 controls by nextgeneration sequencing. Int J Cancer 141 (1):129-142. doi:10.1002/ijc.30692

18. Patmasiriwat P, Bhothisuwan K, Sinilnikova OM, Chopin S, Methakijvaroon S, Badzioch M, Padungsutt P, Vattanaviboon P, Vattanasapt V, Szabo C, Saunders GF, Goldgar D, Lenoir GM (2002) Analysis of breast cancer susceptibility genes BRCA1 and BRCA2 in Thai familial and isolated early-onset breast and ovarian cancer. Hum Mutat 20 (3):230. doi:10.1002/humu.9049

19. Takol Chareonsirisuthigul BR, Donniphat Dejsuphong, Atchara Tunteera, Sunichya Jadsri, (2016) BRCA1 and BRCA2 Large Genomic Rearrangements Screening in Thai Familial Breast Cancer Patients by Multiplex Ligation-dependent Probe Amplification (MLPA). Naresuan University Journal: Science and Technology (NUJST) (2):100-105\%V 124

20. Robson M, Im SA, Senkus E, Xu B, Domchek SM, Masuda N, Delaloge S, Li W, Tung N, Armstrong A, Wu W, Goessl C, Runswick S, Conte P (2017) Olaparib for Metastatic Breast Cancer in Patients with a Germline BRCA Mutation. N Engl J Med 377 (6):523-533. doi:10.1056/NEJMoa1706450

21. Hortobagyi GN, Connolly JL, D’Orsi CJ, Edge SB, Mittendorf EA, Rugo HS, Solin LJ, Weaver DL, Winchester DJ, Giuliano A (2017) Breast. In: Amin MB, Edge SB (eds) AJCC cancer staging manual. 8th edn. springer, New York, pp 589-636

22. Focke CM, van Diest PJ, Decker T (2016) St Gallen 2015 subtyping of luminal breast cancers: impact of different Ki67-based proliferation assessment methods. Breast Cancer Res Treat 159 (2):257-263. doi:10.1007/s10549-016-3950-5

23. Church DM, Schneider VA, Graves T, Auger K, Cunningham F, Bouk N, Chen H-C, Agarwala R, McLaren WM, Ritchie GRS, Albracht D, Kremitzki M, Rock S, Kotkiewicz H, Kremitzki C, Wollam A, Trani L, Fulton L, Fulton R, Matthews L, Whitehead S, Chow W, Torrance J, Dunn M, Harden G, Threadgold G, Wood J, Collins J, Heath P, Griffiths G, Pelan S, Grafham D, Eichler EE, Weinstock G, Mardis ER, Wilson RK, Howe K, Flicek P, Hubbard T (2011) Modernizing reference genome assemblies. PLoS Biol 9 (7):e1001091-e1001091. doi:10.1371/journal.pbio.1001091

24. Genome Reference Consortium (2009) Genome Reference Consortium Human Build 37 (GRCh37). Database (GenBank or RefSeq) https://www.ncbi.nlm.nih.gov/pubmed/.

25. Richards S, Aziz N, Bale S, Bick D, Das S, Gastier-Foster J, Grody WW, Hegde M, Lyon E, Spector E, Voelkerding K, Rehm HL, Committee ALQA (2015) Standards and guidelines for the interpretation of sequence variants: a joint consensus recommendation of the American College of Medical Genetics and Genomics and the Association for Molecular Pathology. Genet Med 17 (5):405-424. doi:10.1038/gim.2015.30

26. StataCrop. (2019) Stata Statistical Software: Release 16. Collage Station, TX. StataCorp LLC,

27. Ang P, Lim IH, Lee TC, Luo JT, Ong DC, Tan PH, Lee AS (2007) BRCA1 and BRCA2 mutations in an Asian clinic-based population detected using a comprehensive strategy. Cancer Epidemiol Biomarkers Prev 16 (11):2276-2284. doi:10.1158/1055-9965.EPI-07-0403

28. Bhaskaran SP, Chandratre K, Gupta H, Zhang L, Wang X, Cui J, Kim YC, Sinha S, Jiang L, Lu B, Wu X, Qin Z, Huang T, Wang SM (2019) Germline variation in BRCA1/2 is highly ethnic-specific: Evidence from over 30,000 Chinese hereditary breast and ovarian cancer patients. Int J Cancer 145 (4):962-973. doi:10.1002/ijc.32176

29. Landrum MJ, Lee JM, Benson M, Brown GR, Chao C, Chitipiralla S, Gu B, Hart J, Hoffman D, Jang W, Karapetyan K, Katz K, Liu C, Maddipatla Z, Malheiro A, McDaniel K, Ovetsky M, Riley G, Zhou G, Holmes JB, Kattman BL, Maglott DR (2018) ClinVar: improving access to variant interpretations and supporting evidence. Nucleic Acids Res 46 (D1):D1062-D1067. doi:10.1093/nar/gkx1153

30. Stenson PD, Mort M, Ball EV, Chapman M, Evans K, Azevedo L, Hayden M, Heywood S, Millar DS, Phillips AD, Cooper DN (2020) The Human Gene Mutation Database $(\operatorname{HGMD}((\mathrm{R})))$ : optimizing its use in a clinical diagnostic or research setting. Hum Genet 139 (10):1197-1207. doi:10.1007/s00439-02002199-3

31. Manchana T, Phowthongkum P, Teerapakpinyo C (2019) Germline mutations in Thai patients with nonmucinous epithelial ovarian cancer. World J Clin Oncol 10 (11):358-368. doi:10.5306/wjco.v10.i11.358

32. Lertkhachonsuk AA, Suprasert P, Manchana T, Kittisiam T, Kantathavorn N, Chansoon T, Khunamornpong S, Pohthipornthawat N, Tangjitgamol S, Luasiripanthu T, Teerapakpinyo C, Shuangshot S, lemwimangsa N, Chantratita W (2020) Prevalence of Tissue BRCA Gene Mutation in Ovarian, Fallopian Tube, and Primary Peritoneal Cancers: A Multi-Institutional Study. Asian Pac J Cancer Prev 21 (8):2381-2388. doi:10.31557/APJCP.2020.21.8.2381

33. Berry DA, Parmigiani G, Sanchez J, Schildkraut J, Winer E (1997) Probability of carrying a mutation of breast-ovarian cancer gene BRCA1 based on family history. J Natl Cancer Inst 89 (3):227-238. doi:10.1093/jnci/89.3.227

34. Silver DP, Livingston DM (2012) Mechanisms of BRCA1 tumor suppression. Cancer Discov 2 (8):679-684. doi:10.1158/2159-8290.CD-12-0221

35. Kim EK, Park SY, Kim SW (2020) Clinicopathological characteristics of BRCA-associated breast cancer in Asian patients. J Pathol Transl Med 54

(4):265-275. doi:10.4132/jptm.2020.04.07 
36. Han SA, Kim SW, Kang E, Park SK, Ahn SH, Lee MH, Nam SJ, Han W, Bae YT, Kim HA, Cho YU, Chang MC, Paik NS, Hwang KT, Kim SJ, Noh DY, Choi DH, Noh WC, Kim LS, Kim KS, Suh YJ, Lee JE, Jung Y, Moon BI, Yang JH, Son BH, Yom CK, Kim SY, Lee H, Jung SH, Group KR, the Korean Breast Cancer S (2013) The prevalence of BRCA mutations among familial breast cancer patients in Korea: results of the Korean Hereditary Breast Cancer study. Fam Cancer 12 (1):75-81. doi:10.1007/s10689-012-9578-7

37. Vocka M, Zimovjanova M, Bielcikova Z, Tesarova P, Petruzelka L, Mateju M, Krizova L, Kotlas J, Soukupova J, Janatova M, Zemankova P, Kleiblova P, Novotny J, Konopasek B, Chodacka M, Brychta M, Sochor M, Smejkalova-Musilova D, Cmejlova V, Kozevnikovova R, Miskarova L, Argalacsova S, Stolarova L, Lhotova K, Borecka M, Kleibl Z (2019) Estrogen Receptor Status Oppositely Modifies Breast Cancer Prognosis in BRCA1/BRCA2 Mutation Carriers Versus NonCarriers. Cancers (Basel) 11 (6). doi:10.3390/cancers11060738

38. Vaziri SA, Krumroy LM, Elson P, Budd GT, Darlington G, Myles J, Tubbs RR, Casey G (2001) Breast tumor immunophenotype of BRCA1-mutation carriers is influenced by age at diagnosis. Clin Cancer Res 7 (7):1937-1945

39. Foulkes WD, Metcalfe K, Sun P, Hanna WM, Lynch HT, Ghadirian P, Tung N, Olopade OI, Weber BL, McLennan J, Olivotto IA, Begin LR, Narod SA (2004) Estrogen receptor status in BRCA1- and BRCA2-related breast cancer: the influence of age, grade, and histological type. Clin Cancer Res 10 (6):2029-2034. doi:10.1158/1078-0432.ccr-03-1061

40. Baretta Z, Mocellin S, Goldin E, Olopade OI, Huo D (2016) Effect of BRCA germline mutations on breast cancer prognosis: A systematic review and meta-analysis. Medicine (Baltimore) 95 (40):e4975. doi:10.1097/MD.0000000000004975

41. Zhu Y, Wu J, Zhang C, Sun S, Zhang J, Liu W, Huang J, Zhang Z (2016) BRCA mutations and survival in breast cancer: an updated systematic review and meta-analysis. Oncotarget 7 (43):70113-70127. doi:10.18632/oncotarget.12158

42. De Talhouet S, Peron J, Vuilleumier A, Friedlaender A, Viassolo V, Ayme A, Bodmer A, Treilleux I, Lang N, Tille JC, Chappuis PO, Buisson A, Giraud S, Lasset C, Bonadona V, Tredan O, Labidi-Galy SI (2020) Clinical outcome of breast cancer in carriers of BRCA1 and BRCA2 mutations according to molecular subtypes. Sci Rep 10 (1):7073. doi:10.1038/s41598-020-63759-1

43. Kim H, Choi DH, Park W (2020) Germline BRCA Mutation and Clinical Outcomes in Breast Cancer Patients Focusing on Survival and Failure Patterns: A Long-Term Follow-Up Study of Koreans. Medicina (Kaunas) 56 (10). doi:10.3390/medicina56100514

\section{Tables}

Table 1 Details of breast cancer in BRCA carriers

\begin{tabular}{|c|c|c|c|c|c|c|c|c|c|c|c|}
\hline \multirow{2}{*}{$\begin{array}{l}\text { Age } \\
\text { (years) }\end{array}$} & \multirow[t]{2}{*}{ Sex } & \multirow[t]{2}{*}{ Histology } & \multirow{2}{*}{$\begin{array}{l}\text { Luminal } \\
\text { subtype }\end{array}$} & \multirow[t]{2}{*}{ Stage } & \multirow[t]{2}{*}{ Uni/Bilateral } & \multirow{2}{*}{$\begin{array}{l}2^{\text {nd }} \\
\text { primary } \\
\text { cancer }\end{array}$} & \multirow{2}{*}{$\begin{array}{l}\text { Recurrence/ } \\
\text { Metastasis }\end{array}$} & \multicolumn{4}{|c|}{ BRCA1/2 mutations } \\
\hline & & & & & & & & $\begin{array}{l}\text { BRCA1/2 } \\
\text { gene }\end{array}$ & $\begin{array}{l}\text { Nucleotide } \\
\text { change }\end{array}$ & $\begin{array}{l}\text { Protein } \\
\text { change }\end{array}$ & $T$ \\
\hline 40 & $\mathrm{~F}$ & IDC & Unknown & IA & Unilateral & $\begin{array}{l}\text { Ovarian } \\
\text { cancer }\end{array}$ & & BRCA1 & c. $5072 C>A$ & p.Thr1691Lys & $\Lambda$ \\
\hline 45 & $\mathrm{~F}$ & ILC & $\begin{array}{l}\text { HER2 - } \\
\text { Luminal B }\end{array}$ & IA & Unilateral & & & BRCA1 & c.2643dupA & p.Cys882Metfs & $\mathrm{F}$ \\
\hline 45 & $\mathrm{~F}$ & IDC & $\begin{array}{l}\text { HER2 - } \\
\text { Luminal B }\end{array}$ & $\| \mathrm{A}$ & Unilateral & $\begin{array}{l}\text { Ovarian } \\
\text { cancer }\end{array}$ & & BRCA1 & c. $3748 \mathrm{G}>\mathrm{T}$ & p.Glu1250Ter & $\Lambda$ \\
\hline 27 & $\mathrm{~F}$ & IDC & $\begin{array}{l}\text { HER2 - } \\
\text { Luminal B }\end{array}$ & IIB & Unilateral & & $\begin{array}{l}\text { Liver } \\
\text { metastasis }\end{array}$ & BRCA1 & c. $4987-1 G>C$ & $?$ & $\begin{array}{l}S \\
a\end{array}$ \\
\hline 36 & $\mathrm{~F}$ & IDC & $\begin{array}{l}\text { HER2 - } \\
\text { Luminal B }\end{array}$ & IIB & Unilateral & $\begin{array}{l}\text { Ovarian } \\
\text { cancer }\end{array}$ & & BRCA1 & c. $2500 \mathrm{G}>\mathrm{T}$ & p.Gly834Ter & $\Lambda$ \\
\hline 46 & $\mathrm{~F}$ & IDC & Unclassified & IIB & Bilateral & & & BRCA1 & c. $5074+3 A>G$ & $?$ & $S$ \\
\hline 76 & $\mathrm{~F}$ & IDC & $\begin{array}{l}\text { HER2 - } \\
\text { Luminal B }\end{array}$ & IIB & Unilateral & PPC & & BRCA2 & c. $9382 C>T$ & p.Arg3128Ter & $\Lambda$ \\
\hline 37 & $\mathrm{~F}$ & IDC & $\begin{array}{l}\text { HER2 - } \\
\text { Luminal B }\end{array}$ & IIB & Unilateral & & & BRCA2 & c.5116_5119delAATA & p.Asn1706Leufs & $\mathrm{F}$ \\
\hline 35 & $\mathrm{~F}$ & IDC & $\begin{array}{l}\text { HER2 - } \\
\text { Luminal B }\end{array}$ & IIB & Bilateral & & & BRCA2 & c. $2380 \mathrm{del} A$ & p.Met794Cysfs & $\mathrm{F}$ \\
\hline 36 & $\mathrm{~F}$ & IDC & $\begin{array}{l}\text { HER2 + } \\
\text { Luminal B }\end{array}$ & IIIA & Bilateral & & & BRCA2 & c.8855dupT & p.Met2952llefs & $\mathrm{F}$ \\
\hline 53 & $\mathrm{~F}$ & IDC & $\begin{array}{l}\text { HER2 - } \\
\text { Luminal B }\end{array}$ & IIIC & Unilateral & & & BRCA2 & c. $6229 \mathrm{~A}>\mathrm{T}$ & p.Lys2077Ter & $\Lambda$ \\
\hline 40 & $\mathrm{~F}$ & IDC & $\begin{array}{l}\text { HER2 + } \\
\text { Luminal B }\end{array}$ & IIIC & Unilateral & & $\begin{array}{l}\text { Liver } \\
\text { metastasis }\end{array}$ & BRCA2 & c.8888_8889insA & p.Arg2964Lysfs & $\mathrm{F}$ \\
\hline
\end{tabular}


F, Female; HER2, human epidermal growth factor receptor; IDC, Invasive ductal carcinoma; ILC, Invasive lobular carcinoma; PPC, Primary peritoneal cancer

Table 2 Demographic data of breast cancer patients according to BRCA status 


\begin{tabular}{|c|c|c|c|c|c|}
\hline Characteristics & Total & BRCA1/2 carriers & Patients with VUS & BRCA1/2 & P-value \\
\hline \multirow[t]{2}{*}{$\mathrm{N},(\%)$} & $N=67$ & $\mathrm{~N}=12$ & $N=4$ & Non-carriers & \\
\hline & & & & $N=51$ & \\
\hline Sex & & & & & 1.000 \\
\hline Female & $66(98.5)$ & $12(100)$ & $4(100)$ & $50(98.0)$ & \\
\hline Male & $1(1.5)$ & 0 & 0 & $1(2.0)$ & \\
\hline Age (mean $\pm S D$, years) & $42.0 \pm 10.3$ & $43.0 \pm 12.4$ & $42.0 \pm 8.1$ & $41.7 \pm 10.1$ & 0.590 \\
\hline Age at diagnosis & & & & & 1.000 \\
\hline$£ 40$ years & $36(53.7)$ & $7(58.3)$ & $2(50.0)$ & $27(52.9)$ & \\
\hline$>40$ years & $31(46.3)$ & $5(41.7)$ & $2(50.0)$ & $24(47.1)$ & \\
\hline Cancer affected: breast cancer only & & & & & 0.455 \\
\hline Unilateral & $57(85.0)$ & $9(75.0)$ & $4(100)$ & $44(86.3)$ & \\
\hline Metachronous bilateral & $6(9.0)$ & $1(8.3)$ & 0 & $5(9.8)$ & \\
\hline Synchronous bilateral & $4(6.0)$ & $2(16.7)$ & 0 & $2(3.9)$ & \\
\hline ECOG performance status & & & & & 0.239 \\
\hline 0 & $66(98.5)$ & $11(91.7)$ & $4(100)$ & $51(100)$ & \\
\hline 1 & $1(1.5)$ & $1(8.3)$ & 0 & 0 & \\
\hline TNM staging & & & & & 0.367 \\
\hline 0 & $3(4.6)$ & 0 & 0 & $3(6.1)$ & \\
\hline I & $19(29.2)$ & $2(16.7)$ & 0 & $17(34.7)$ & \\
\hline ॥ & $32(49.2)$ & $7(58.3)$ & $3(75.0)$ & $22(44.9)$ & \\
\hline III & $11(16.9)$ & $3(25.0)$ & $1(25.0)$ & $7(14.3)$ & \\
\hline \multicolumn{6}{|l|}{ Missing data $(\mathrm{N}=2)$} \\
\hline ER & & & & & 0.072 \\
\hline Negative & $22(35.5)$ & $1(9.1)$ & $1(25.0)$ & $20(42.5)$ & \\
\hline Positive & $40(64.5)$ & $10(90.9)$ & $3(75.0)$ & $27(57.5)$ & \\
\hline \multicolumn{6}{|l|}{ Missing data $(\mathrm{N}=5)$} \\
\hline PR & & & & & 0.120 \\
\hline Negative & $21(35.0)$ & $1(10.0)$ & $1(25.0)$ & $19(41.3)$ & \\
\hline Positive & $39(65.0)$ & $9(90.0)$ & $3(75.0)$ & $27(58.7)$ & \\
\hline \multicolumn{6}{|l|}{ Missing data $(\mathrm{N}=7)$} \\
\hline HER2 & & & & & 0.159 \\
\hline Negative & $40(69.0)$ & $8(80.0)$ & $1(25.0)$ & $31(70.4)$ & \\
\hline Equivocal & $1(3.4)$ & 0 & $1(25.0)$ & $1(2.3)$ & \\
\hline Overexpression (Positive) & $16(27.6)$ & $2(20.0)$ & $2(50.0)$ & $12(27.3)$ & \\
\hline \multicolumn{6}{|l|}{ Missing data $(\mathrm{N}=9)$} \\
\hline Ki-67 & & & & & 1.000 \\
\hline$<20 \%$ & $7(13.2)$ & $1(11.1)$ & 0 & $6(15.0)$ & \\
\hline${ }^{3} 20 \%$ & $46(86.8)$ & $8(88.9)$ & $4(100)$ & $34(85.0)$ & \\
\hline \multicolumn{6}{|l|}{ Missing data $(\mathrm{N}=14)$} \\
\hline Luminal subtypes & & & & & 0.058 \\
\hline Luminal-A & $6(9.0)$ & 0 & 0 & $6(11.8)$ & \\
\hline HER2-negative Luminal-B & $19(28.3)$ & $8(66.6)$ & 0 & $11(21.6)$ & \\
\hline HER2-positive Luminal-B & $13(19.4)$ & $2(16.7)$ & $2(50.0)$ & $9(17.6)$ & \\
\hline
\end{tabular}

Page 10/15 


\begin{tabular}{|c|c|c|c|c|c|}
\hline Characteristics & Total & BRCA1/2 carriers & Patients with VUS & BRCA1/2 & P-value \\
\hline \multirow[t]{2}{*}{$\mathrm{N},(\%)$} & $N=67$ & $N=12$ & $N=4$ & Non-carriers & \\
\hline & & & & $N=51$ & \\
\hline TNBC & $15(22.4)$ & 0 & $1(25.0)$ & $14(27.4)$ & \\
\hline HER2-positive Non-luminal & $3(4.5)$ & 0 & 0 & $3(5.9)$ & \\
\hline Unclassified & $11(16.4)$ & $2(16.7)$ & $1(25.0)$ & $8(15.7)$ & \\
\hline Surgery & & & & & 0.257 \\
\hline Mastectomy & $51(77.3)$ & 11 (91.7) & $4(100)$ & $36(72.0)$ & \\
\hline BCS & $15(22.7)$ & $1(8.3)$ & 0 & $14(28.0)$ & \\
\hline \multicolumn{6}{|l|}{ Missing data $(\mathrm{N}=1)$} \\
\hline Adjuvant chemotherapy & & & & & 0.639 \\
\hline No & $20(29.8)$ & $2(16.7)$ & $1(25.0)$ & 17 (33.3) & \\
\hline Yes & $47(70.2)$ & 10 (83.3) & $3(75.0)$ & $34(67.7)$ & \\
\hline Hormone therapy & & & & & 0.653 \\
\hline No & $24(35.8)$ & $3(25.0)$ & $1(25.0)$ & $20(39.2)$ & \\
\hline Yes & $43(64.2)$ & $9(75.0)$ & $3(75.0)$ & $31(60.8)$ & \\
\hline Adjuvant Radiation & & & & & 0.261 \\
\hline No & $29(43.3)$ & $5(41.7)$ & 0 & $24(47.1)$ & \\
\hline Yes & $38(56.7)$ & 7 (58.3) & $4(100)$ & 27 (52.9) & \\
\hline
\end{tabular}

BCS, breast conservation surgery; ECOG, Eastern Cooperative Oncology Group; ER, estrogen receptor; HER2, human epidermal growth factor receptor; PR, progesterone receptor; SD, standard deviation; TNBC, triple-negative breast cancer

Table 3 Comparison of breast cancer in BRCA1 and BRCA2 carriers 


\begin{tabular}{|c|c|c|c|}
\hline \multirow[t]{2}{*}{ Characteristics } & BRCA1 carriers & BRCA2 carriers & P-value \\
\hline & $N=6$ & $N=6$ & \\
\hline Age (mean \pm SD, years) & $39.8 \pm 7.4$ & $46.2 \pm 16.0$ & 0.400 \\
\hline Age at diagnosis & & & 1.00 \\
\hline$\leq 40$ years & $3(50.0)$ & $4(66.7)$ & \\
\hline$>40$ years & $3(50.0)$ & $2(33.3)$ & \\
\hline ER & & & 0.455 \\
\hline Negative & $1(20.0)$ & 0 & \\
\hline Positive & $4(80.0)$ & $6(100)$ & \\
\hline \multicolumn{4}{|l|}{ Missing data $(\mathrm{N}=1)$} \\
\hline PR & & & 0.400 \\
\hline Negative & $1(25.0)$ & 0 & \\
\hline Positive & $3(75.0)$ & $6(100)$ & \\
\hline \multicolumn{4}{|l|}{ Missing data $(\mathrm{N}=2)$} \\
\hline HER2 & & & 0.467 \\
\hline Negative & $4(100)$ & $4(66.7)$ & \\
\hline Equivocal & 0 & 0 & \\
\hline Overexpression & 0 & $2(33.3)$ & \\
\hline \multicolumn{4}{|l|}{ Missing data $(\mathrm{N}=2)$} \\
\hline Luminal subtypes & & & 0.212 \\
\hline Luminal-A & 0 & 0 & \\
\hline HER2-negative Luminal-B & $4(66.7)$ & $4(66.7)$ & \\
\hline HER2-positive Luminal-B & 0 & $2(33.3)$ & \\
\hline TNBC & 0 & 0 & \\
\hline HER2-positive Non-luminal & 0 & 0 & \\
\hline Unclassified/Unknown & $2(33.33)$ & 0 & \\
\hline Stage & & & 0.091 \\
\hline 1 & $2(33.3)$ & 0 & \\
\hline II & $4(66.7)$ & $3(50.0)$ & \\
\hline III & 0 & $3(50.0)$ & \\
\hline
\end{tabular}

ER, estrogen receptor; HER2, human epidermal growth factor receptor; PR, progesterone receptor; SD, standard deviation; TNBC, triple-negative breast cancer

Table 4 Cox regression analysis of prognostic factors associated with 3-year disease-free survival 


\begin{tabular}{|c|c|c|c|c|c|c|}
\hline \multirow[t]{2}{*}{ Factors } & \multirow[t]{2}{*}{$N$} & \multirow[t]{2}{*}{ 3-year DFS (\%) } & \multicolumn{2}{|l|}{ Univariate analysis } & \multicolumn{2}{|l|}{ Multivariate analysis } \\
\hline & & & $\mathrm{HR}(95 \% \mathrm{Cl})$ & P-value & $\mathrm{HR}(95 \% \mathrm{Cl})$ & P-value \\
\hline \multicolumn{7}{|l|}{ BRCA } \\
\hline BRCA $1 / 2$ Non-carriers & 50 & 90.3 & 1 & & 1 & \\
\hline BRCA1/2 Carriers & 12 & 81.5 & $2.04(0.64,6.49)$ & 0.229 & $2.50(0.48,12.97)$ & 0.275 \\
\hline Patients with VUS & 4 & 79.0 & $1.60(0.20,12.99)$ & 0.658 & $1.25(0.12,12.81)$ & 0.852 \\
\hline \multicolumn{7}{|l|}{ Age } \\
\hline$£ 40$ years & 36 & 90.8 & 1 & & & \\
\hline$>40$ years & 30 & 84.4 & $1.19(0.42,3.42)$ & 0.741 & & \\
\hline \multicolumn{7}{|l|}{ T stage } \\
\hline Tis & 3 & 100 & - & & & \\
\hline $\mathrm{T} 1$ & 22 & 100 & 1 & & & \\
\hline $\mathrm{T} 2$ & 30 & 80.1 & $4.32(1.01,18.42)$ & 0.048 & & \\
\hline T3 & 10 & 78.8 & $4.12(0.90,18.91)$ & 0.069 & & \\
\hline \multicolumn{7}{|l|}{ Lymph node metastasis } \\
\hline Negative & 36 & 90.4 & 1 & & & \\
\hline Positive & 29 & 84.3 & $1.84(0.58,5.79)$ & 0.299 & & \\
\hline \multicolumn{7}{|l|}{ TNM Staging } \\
\hline 0 & 3 & 100 & - & & - & \\
\hline I & 19 & 100 & 1 & & 1 & \\
\hline II & 32 & 84.8 & $2.88(0.73,11.33)$ & 0.131 & $6.32(0.90,44.48)$ & 0.064 \\
\hline III & 11 & 72.7 & $6.82(1.12,41.33)$ & 0.037 & $16.30(1.38,192.81)$ & 0.027 \\
\hline \multicolumn{7}{|l|}{ ER status } \\
\hline Negative & 22 & 76.8 & 1 & & & \\
\hline Positive & 40 & 92.1 & $0.49(0.16,1.46)$ & 0.198 & & \\
\hline \multicolumn{7}{|l|}{ PR status } \\
\hline Negative & 21 & 76.7 & 1 & & & \\
\hline Positive & 39 & 91.7 & $0.67(0.20,2.22)$ & 0.515 & & \\
\hline \multicolumn{7}{|l|}{ HER2 status } \\
\hline Negative & 40 & 82.4 & 1 & & & \\
\hline Equivocal & 2 & 100 & - & & & \\
\hline Overexpression & 16 & 93.8 & $0.48(0.10,2.31)$ & 0.359 & & \\
\hline \multicolumn{7}{|l|}{$\mathrm{Ki}-67$} \\
\hline$<20 \%$ & 7 & 85.7 & 1 & & & \\
\hline${ }^{3} 20 \%$ & 46 & 84.3 & $0.97(0.12,8.10)$ & 0.981 & & \\
\hline \multicolumn{7}{|l|}{ Luminal subtype } \\
\hline Luminal-A & 6 & 83.3 & 1 & & 1 & \\
\hline HER2-negative Luminal-B & 15 & 93.8 & $0.46(0.04,4.78)$ & 0.513 & $0.14(0.01,2.30)$ & 0.171 \\
\hline HER2-positive Luminal-B & 13 & 92.3 & $0.33(0.02,5.50)$ & 0.441 & $0.14(0.01,3.01)$ & 0.212 \\
\hline TNBC & 15 & 65.3 & $1.21(0.13,11.16)$ & 0.868 & $1.23(0.13,11.78)$ & 0.866 \\
\hline HER2-positive Non-luminal & 3 & 100 & $0.57(0.03,10.52)$ & 0.706 & $0.72(0.03,16.67)$ & 0.836 \\
\hline Unclassified & 10 & 100 & $0.42(0.04,4.74)$ & 0.487 & $0.65(0.04,11.87)$ & 0.775 \\
\hline \multicolumn{7}{|l|}{ Cancer affected } \\
\hline Unilateral & 56 & 89.3 & 1 & & & \\
\hline
\end{tabular}

Page 13/15 


\begin{tabular}{|llllll|}
\hline Factors & N & 3-year DFS (\%) & Univariate analysis & Multivariate analysis \\
\cline { 5 - 6 } & & & HR $(95 \% \mathrm{Cl})$ & P-value & HR (95\%Cl) \\
\hline Metachronous bilateral & 6 & 66.7 & $7.44(2.26,24.50)$ & 0.001 & P-value \\
\hline Synchronous bilateral & 4 & 100 & $1.77(0.21,14.79)$ & 0.599 \\
\hline Adjuvant treatment & & & & \\
\hline No & 19 & 94.1 & 1 & \\
\hline Yes & 47 & 85.1 & $2.44(0.66,9.03)$ & 0.181 \\
\hline Surgery treatment & & & & \\
\hline BCS & 15 & 92.3 & 1 & \\
\hline Mastectomy & 51 & 86.5 & $2.07(0.46,9.29)$ & 0.342 \\
\hline Radiation therapy & & & & 1 & \\
\hline No & 28 & 88.9 & $1.03(0.35,2.97)$ & 0.961 \\
\hline Yes & 38 & 86.5 & & \\
\hline
\end{tabular}

BCS, breast conservation surgery; Cl, confidence interval; DFS, disease free survival; ER, estrogen receptor; HER2, human epidermal growth factor receptor; HR, hazard ratio; PR, progesterone receptor; T, tumor size; Tis, carcinoma in situ; TNBC, triple-negative breast cancer; VUS, Variants of Uncertain Significance

\section{Figures}

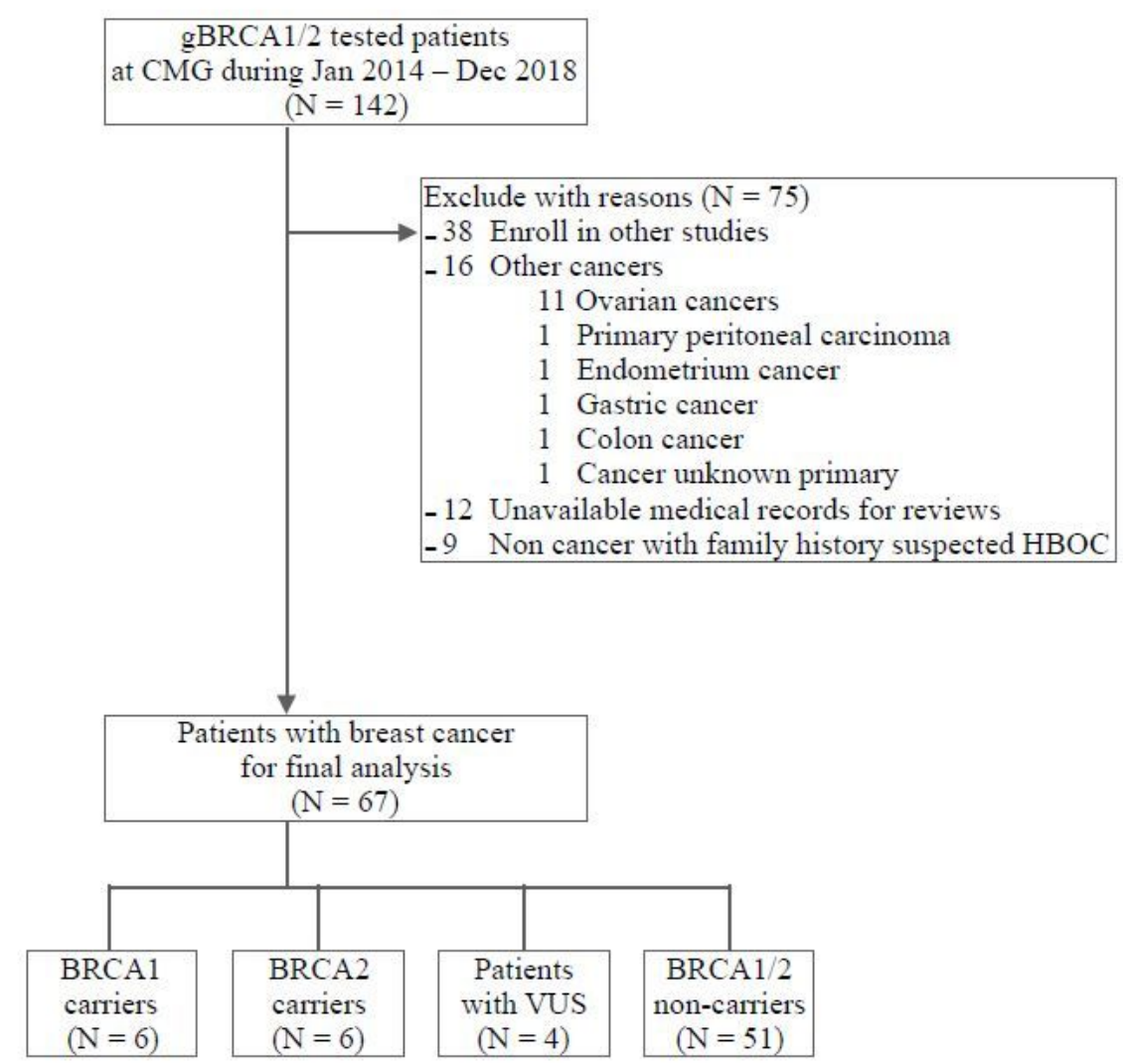

\section{Figure 1}

Patient selection 


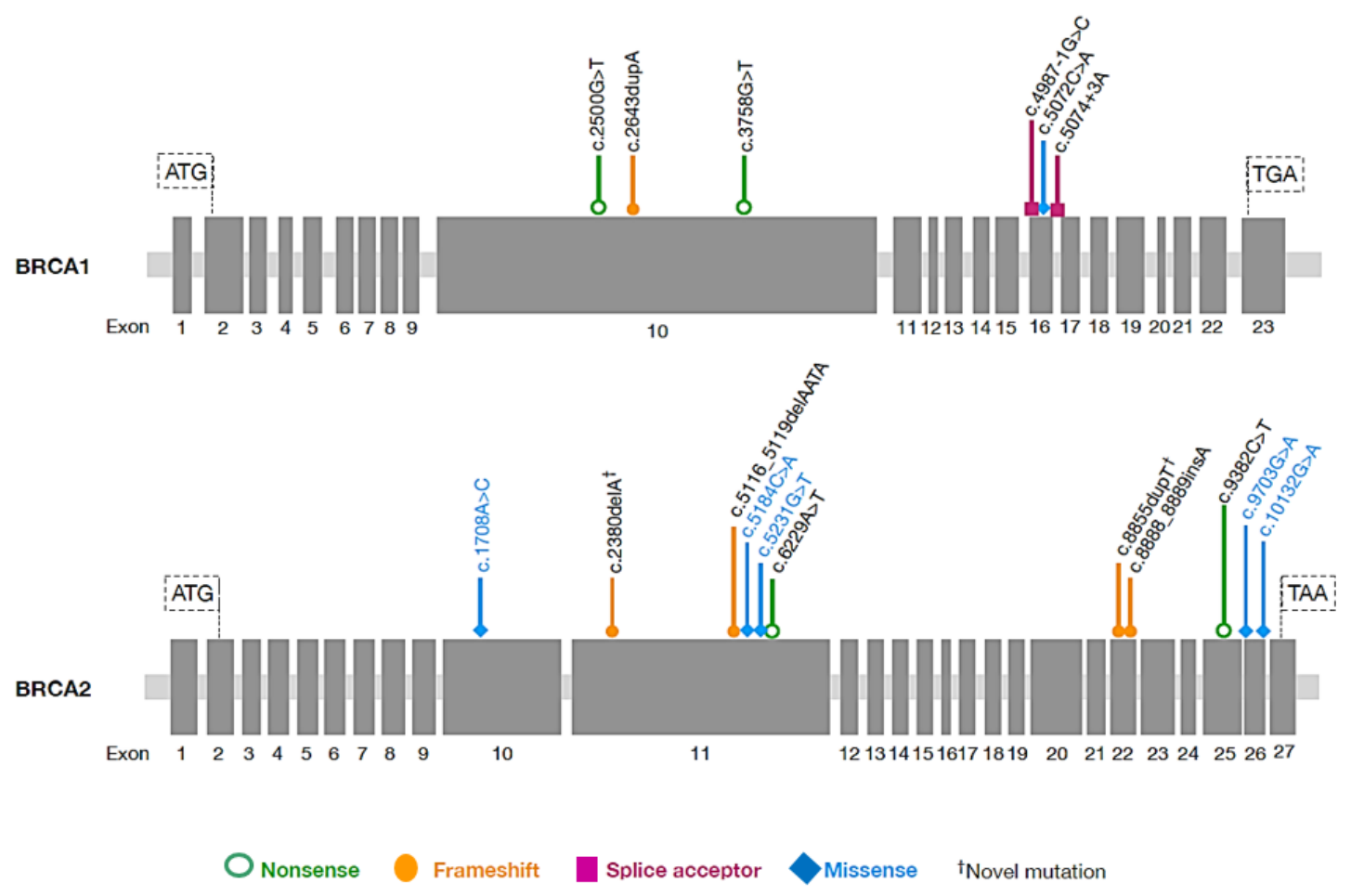

\section{Figure 2}

Diagram of BRCA1 and BRCA2 genes, indicating the position of pathogenic variants identified here. Exons are indicated by boxes and numbered according to the Locus Reference Genomic (LRG) description. The ATG translation initiation sites and termination codons are indicated by longer lines. Black letters = pathogenic mutation in BRCA1 and BRCA2, Blue letters = VUS in BRCA2 